\title{
Energy-efficient resin wafer electrodeionization for impaired water reclamation
}

Seth W Snyder, Hwong-Wen Ma, Yupo J. Lin, Pen-Chi Chiang, Shu-Yuan Pan

February 2018

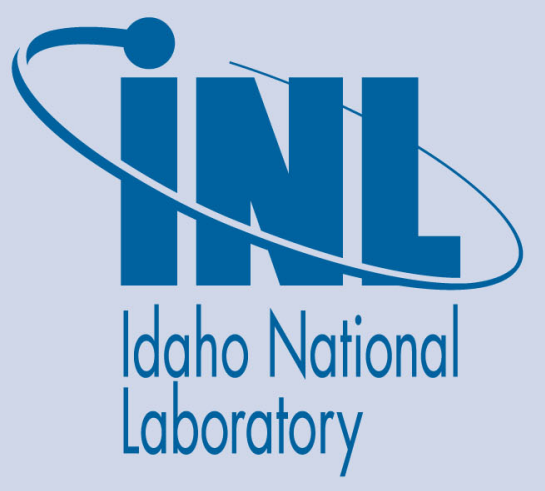

The INL is a U.S. Department of Energy National Laboratory operated by Battelle Energy Alliance 


\section{Energy-efficient resin wafer electrodeionization for impaired water reclamation}

Seth W Snyder, Hwong-Wen Ma, Yupo J. Lin, Pen-Chi Chiang, Shu-Yuan Pan

February 2018

Idaho National Laboratory Idaho Falls, Idaho 83415

http://www.inl.gov

Prepared for the U.S. Department of Energy Office of Nuclear Energy Under DOE Idaho Operations Office

Contract DE-AC07-05ID14517 


\title{
Energy-Efficient Resin Wafer Electrodeionization for Impaired Water Reclamation
}

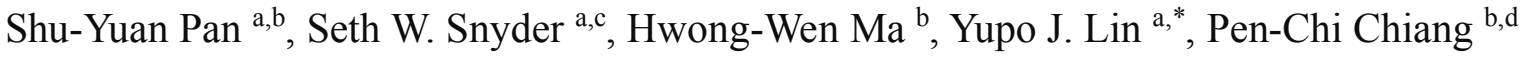 \\ ${ }^{a}$ Energy Systems Division, Argonne National Laboratory, Argonne, Illinois 60439, United States. \\ ${ }^{\mathrm{b}}$ Graduate Institute of Environmental Engineering, National Taiwan University, Taipei 10673, Taiwan. \\ ${ }^{c}$ Clean Energy and Transportation, Idaho National Laboratory, Idaho Falls, ID 83415, United States. \\ ${ }^{\mathrm{d}}$ Carbon Cycle Research Center, National Taiwan University, Taipei 10672, Taiwan. \\ * Corresponding author at 9700 S Cass Ave., Argonne, IL 60439, United States. E-mail address: yplin@anl.gov \\ (Y.J. Lin)
}

\section{Abstract}

A robust ion-exchange resin wafer electrodeionization technology was used to demonstrate the energy efficiency of impaired water desalination. The loose ion exchange resin beads used in conventional electrodeionization were immobilized and molded to form a porous resin wafer material. In this study, the energy efficiency of brackish water desalination using resin wafer electrodeionization was evaluated along with salt removal ratio, current efficiency and productivity. Several key operating factors, including treatment time, applied electrical energy and feed flow rate were selected through experimental design. In addition, the removal rate constant in resin wafer electrodeionization was determined via a pseudo firstorder kinetic model, and then correlated with operation parameters. Furthermore, the prediction models of the productivity and energy consumption were established using response surface methodology. Results suggest that resin wafer electrodeionization can improve energy efficiency to greater than $35 \%$ in comparison to reverse osmosis (normally $\sim 12 \%$ ) for impaired water desalination. The energy consumption of resin wafer electrodeionization was found to be $0.35-0.66 \mathrm{kWh} / \mathrm{m}^{3}$ with productivity of $20.1-44.7$ $\mathrm{L} / \mathrm{hr} / \mathrm{m}^{2}$ (i.e., 5.3-11.8 gal $/ \mathrm{hr} / \mathrm{m}^{2}$ ) for brackish water desalination. Furthermore, a preliminary economic 
evaluation on impaired water desalination using resin wafer electrodeionization comparable to commercial reverse osmosis process was provided. It suggests that resin wafer electrodeionization offers the potential for an abundant source of fresh water from impaired water desalination at a cost-effective manner, which should be viewed as a crucial component in the portfolio of water supply options.

Keywords: brackish water; nonlinear mathematical programming; response surface methodology; current efficiency; energy consumption; productivity 


\section{Introduction}

Freshwater stress and scarcity is one of the most challenging society issues (OECD/IEA, 2013; Sahin et al., 2015). Desalination of seawater and/or impaired water should be a resource-efficient solution in the face of an increase in regional freshwater scarcity; however, desalination processes are energy intensive in comparison to direct freshwater use. New approaches to reducing the energy for treating brackish and impaired water could help alleviate freshwater stress (USDOE, 2014). The theoretical minimum energy for desalination is achieved when the separation occurs as a reversible thermodynamic process, and is a function of the water recovery percentage and salinity of the feedwater (Elimelech and Phillip, 2011). While the practical energy required for desalination is dependent on the fundamental removal mechanism and desalination method (Porada et al., 2013).

Existing technologies, including multi-effect distillation (MED) (Drioli et al., 2015) and reverse osmosis (RO) (Elimelech and Phillip, 2011), are well established for seawater ( $\sim 35 \mathrm{~g} / \mathrm{L} \mathrm{NaCl})$ desalination. These technologies remove water from the saline source and have not been optimized for impaired water

(a salinity of 1-20 g/L) desalination. They operate far from the thermodynamic efficiency limit of desalination. With RO, energy efficiency improves only slightly with decreasing feedwater salinity. Therefore, the energy efficiency per unit of salt removed decreases with decreasing salinity. Significant difference in energy efficiency of RO was realized from near maximum $65 \%$ for seawater desalination to $11 \%$ for impaired water desalination. In contrast, electrically-driven processes, such as electrodialysis (ED), remove salts or ions from the feedwater rather than the water from the feed. Energy use scales near linearly with the feedwater salinity and they offer superior efficiency at lower salinity in comparison to pressure-driven or temperature-driven processes.

To improve energy efficiency beyond RO for impaired water desalination (i.e., $<1.0 \mathrm{kWh} / \mathrm{m}^{3}$ ), different advanced processes, such as forward osmosis (FO) (Luo et al., 2014), capacitive deionization 
(CDI) (Bian et al., 2015; Dlugolecki and van der Wal, 2013) and modified electrodeionization (EDI) (Alvarado and Chen, 2014; Lu et al., 2015), have been proposed and developed. FO, an osmotically-driven membrane process, is operated under low hydraulic pressure, even under no hydraulic pressure. For brackish water desalination, FO usually requires a post-treatment process, such as pressure-driven membrane processes and thermal processes, to recover product water. Compared to RO (pressure-driven) process, FO exhibits higher water recovery ratio, lower membrane fouling tendency and more energy efficiency (Xu et al., 2017). However, FO technology still suffers from significant issues including (i) slow desalination kinetics, (ii) non-ideal membrane performance such as water recovery efficiency, mechanical strength and fabrication costs, and (iii) membrane fouling and internal concentration polarization. CDI technology removes salts from impaired water by electric field into pore surface electric double layers, a process known as electrosorption (Biesheuvel and Bazant, 2010). When treating brackish water with a salinity of $2.0 \mathrm{~g} / \mathrm{L}, \mathrm{CDI}$ required approximately $0.59 \mathrm{kWh} / \mathrm{m}^{3}$ to recover $70 \%$ of the water at a permeate salinity of $0.5 \mathrm{~g} / \mathrm{L}$ (Welgemoed and Schutte, 2005). However, CDI suffers from considerable challenges, such as (i) high costs for electrode fabrication, (ii) small scale of operation, and (iii) incomplete regeneration of the electrodes (AlMarzooqi et al., 2014).

Electrodeionization (EDI) has being commercially applied to produce ultrapure water in the semiconductor and pharmaceutical industries. Electrically-driven separations processes such as ED and EDI remove charged ions by applying an electric field. Ion exchange (IEX) resins are incorporated into the EDI process channel to provide a pathway for enhanced ion migration. The IEX resins increase conductivity in across the process channel and enable ion transport towards the IEX membranes with low conductivity process water. The IEX resin beads are continuously regenerated electrochemically by protons $\left(\mathrm{H}^{+}\right)$and hydroxyl ions $\left(\mathrm{OH}^{-}\right)$via a water splitting reaction in the applied electric field. For this reason, chemical regeneration is not required in EDI in comparison to a conventional IEX columns process. 
Furthermore, EDI reduces energy use for impaired water desalination in comparison to ED and RO (Zhang et al., 2014).

Conventional EDI processes suffer from inconsistent performance and difficult on-site maintenance due to the use of loose resin beads (Pan et al., 2017). With loose resins, the EDI stack must be handled with care in a controlled environment. Loose IEX beads can also result in channel formation, thereby decreasing ion removal. To overcome the aforementioned barriers, Lin et al. (2008) have developed a resin wafer (RW) material, which is composed of the original loose IEX resins immobilized and molded into a porous and solid matrix, to replace the conventional loose beads in stack. The EDI stack with the prepared RW material, so-called RW-EDI, can significantly improve ionic mobility and also enable local pH control (Arora et al., 2007). The RW-EDI has been successfully applied to several process streams, such as $\mathrm{CO}_{2}$ capture (Datta et al., 2013a), recycling of cooling water in power plants (Gill, 2010), recovery of organic acids (Datta et al., 2014), purification of organic acids incorporated with ionic liquids (Lopez and Hestekin, 2015), treatment of industrial process water (Lopez et al., 2017), deacidification of lignocellulosic hydrolysate liquor (Datta et al., 2013b), and detoxification of biomass slurries (Gurram et al., 2011).

For a cost-effective impaired water desalination, maintaining high performance in both productivity (water recovery ratio) and energy consumption is a critical task to enable significant deployment. High water recovery ratio provides an additional value of decreasing the volume of discharge or reject brine water that must be managed. Therefore, the productivity and energy efficiency for RW-EDI desalination of impaired water were evaluated in this study. The objectives of this study were to (1) evaluate operation conditions including treatment time, applied voltage and feed flow rate on salt removal ratio and current efficiency; (2) determine the salt removal kinetics via a first-order model; (3) establish non-linear models using response surface methodology for balancing productivity and energy consumption; and (4) provide a preliminary economic evaluation on impaired water desalination using RW-EDI compared to RO and 
conventional ED processes.

\section{Materials and Methods}

\subsection{Resin wafer electrodeionization (RW-EDI)}

The impaired water desalination experiments using RW-EDI were conducted in a modified commercial electrodialysis stack (EUR2B-10), purchased from Ameridia Corp. (Somerset, NJ, USA). A four-cell pair configuration RW-EDI device was used for all experiments, where the configuration details are provided in Table 1. Each cell pair in the RW-EDI system contains a diluate compartment (ions depleted) and a concentrate compartment (ions accumulated), separated by cation, anion and bipolar membranes. This combination was repeated for the multi-cell pair configuration. The diluate compartment contains a porous ion-exchange resin wafer, with $195 \mathrm{~cm}^{2}$ cross-section surface area. Resin wafers were fabricated using anion-exchange resin beads, cation-exchange resin beads, a binder polymer and a porogen. The mixture was then heated to around $100{ }^{\circ} \mathrm{C}$ for $1 \mathrm{hr}$, and cast in a mold to form a porous resin wafer. The length and width of the resin wafer is 17.6 and $11.1 \mathrm{~cm}$, respectively. Bipolar membranes were used at both ends of the RW-EDI stack to isolate the electrode rinse solution $\left(2.5 \% \mathrm{Na}_{2} \mathrm{SO}_{4}\right)$ from the process fluid. The membranes are arranged to facilitate unidirectional ion flow under an applied electric field. In other words, ions can only move out from the diluate compartments into concentrate compartments. Two liters of $2.5 \% \mathrm{Na}_{2} \mathrm{SO}_{4}$ were used as electrode rinse solution in the RW-EDI.

\section{$<$ Table 1 $>$}

Fig. 1 shows the schematic diagram of RW-EDI for impaired water desalination in this study. Brackish water covers a range of salinity regimes, i.e., typically from 1 to $15 \mathrm{~g} / \mathrm{L}$ of salt. In this study, synthetic brackish water with a representative concentration of $5 \mathrm{~g} / \mathrm{L} \mathrm{NaCl}$ was used. In each experiment, 
two liters of brackish water were processed for 120 mins. The concentrate tank started with two liters of $0.1 \mathrm{~N} \mathrm{NaCl}$ initial concentration. The flow rate of concentrate stream is fixed at $1100 \mathrm{~mL} / \mathrm{min}$ in all experiments. A DC power (XHR 100-10, Sorensen, AMETEK, Inc., USA) was used to apply constant voltage or current across the electrodes.

\section{$<$ Figure 1 $>$}

\subsection{Key performance indicators}

For impaired water desalination, four key performance indicators should be determined for process evaluation: salt removal ratio $\left(\eta_{r}\right)$, current efficiency $(\mathrm{CE})$, energy consumption $\left(\psi_{c}\right)$, and energy efficiency $\left(\eta_{e}\right)$. The removal ratio $\left(\eta_{r}\right)$ quantifies the fraction of ions removed by the EDI, and is a critical process parameter for process scale-up. The amount of chloride ion removal ratio can be determined using Eq. (1):

$$
\eta_{r}(\%)=\frac{C_{i}-C_{o}}{C_{i}} \times 100
$$

where $C_{\mathrm{i}}$ and $C_{\mathrm{o}}$ are the initial and outflow concentration $(\mathrm{g} / \mathrm{L})$ of chloride ions in solution, respectively.

The removal ratio depends on both the fundamental performance of the materials (e.g., resin and membranes) in the EDI and the operating conditions (e.g., flow rate and applied current).

CE represents the effectiveness of ions transported across the IEX membranes by a given current. which can be determined according to Eq. (2). It is defined as the ratio of the stoichiometric number of electrical charges for the ion migrated to the total electrical charges introduced into the device (Feng et al., 2007).

$$
C E=\frac{z \times F \times n}{\int_{0}^{t} I \times d t}=1.61 \times \frac{Q_{f} \times\left(C_{i}-C_{o}\right) \times z}{M W_{N a C l} \times I \times N_{c p}}
$$


where $z$ is the valence of the ion (equiv/mole); $F$ is the Faraday constant $(96500 \mathrm{~s} \cdot \mathrm{A} / \mathrm{mol}$ ); $n$ is the mole number of the ion migrated (mol); $I$ is the stack current (A); $t$ is the time interval (s); $Q_{\mathrm{f}}$ is the feed flow rate $(\mathrm{mL} / \mathrm{min}) ; M W_{\mathrm{NaCl}}$ is the molecular weight of sodium chloride $(58.44 \mathrm{~g} / \mathrm{mole})$; and $N_{\mathrm{cp}}$ is the number of cell pairs. Typically, current efficiencies greater than $80 \%$ are desirable to minimize energy consumption and operating costs. Low current efficiencies may be attributed from several operation problems, such as excessive water splitting, shunt currents between the electrodes, and back-diffusion of ions from the concentrate to the diluate. Therefore, the relationship of ion removal ratio and the process operation parameters can be clearly understood by CE.

Cost-effective desalination requires both high productivity (recovery ratio) and low energy consumption. The process water productivity $\left(\varphi, \mathrm{L} / \mathrm{hr} / \mathrm{m}^{2}\right)$ can be calculated from the ratio of the feed flow rate to the total active cross section membrane area. On the other hand, the energy consumption ( $\psi_{c}$, $\mathrm{kWh} / \mathrm{m}^{3}$ ), the electric energy used to produce $1 \mathrm{~m}^{3}$ of purified water, can be calculated by Eq. (3):

$$
\psi_{c}\left(\mathrm{kWh} / \mathrm{m}^{3}\right)=\frac{U^{\prime} \times I \times t}{L}=16.7 \times \frac{U^{\prime} \times I}{Q_{p}}
$$

where $U^{\prime}$ is the applied voltage (V); $L$ is the volume of diluted feed water $\left(\mathrm{m}^{3}\right)$; and $Q_{p}$ is the flow rate of produced water $(\mathrm{mL} / \mathrm{min})$.

Another important key performance indicator for desalination process is the energy efficiency $\left(\eta_{e}\right)$, followed by the second law efficiency of the desalination plant. The energy efficiency can be defined as the ratio of the minimum work required for separation (i.e., desalination) to the actual work consumed by a desalination process (Sharqawy et al., 2011), as shown in Eq. (4):

$$
\eta_{e}(\%)=\frac{W_{\text {min }}}{W_{\text {actual }}} \times 100
$$


where $W_{\min }$ is the minimum work of separation as calculated from thermodynamics, and $W_{\text {actual }}$ is the actual work supplied to the separation process. It is noted that a major part of water-energy nexus concerns the energy consumption [Eq. (3)] and energy efficiency [Eq. (4)] for supplying and treating water (OECD/IEA, 2013; USDOE, 2014).

\subsection{Design of Experiments}

Experiments were conducted to evaluate the effect of applied voltage and feed flow rate on the key performance indicators of RW-EDI via a central composite design (CCD). The design of experiments, regression analysis, and analysis of variance (ANOVA) were performed using Design Expert software (ver. 8.0.6, Stat-Ease Inc., USA). A five-level CCD with two factors, including a replicate at factorial, two replicates at axial, and three replicates at the center point was applied, leading to 17 runs for fitting the response surface. CCD is a regression form that is introduced to consider the effect of the interaction among the independent variables (Montgomery, 2017). In the CCD, each process variables are divided into five coded levels (i.e., $-\alpha, 1,0,1$, and $+\alpha$ ). Each of these level corresponds to a variable value by a linear transform of the original data scale, i.e., the highest value of the original variable becomes +1 and the lowest value becomes -1 ; the average of these two values $(+1$ and -1$)$ is assigned to 0 ; the values of $\alpha$ and $+\alpha$ are applied to find the minimum and the maximum values, respectively.

\subsection{Response surface methodology (RSM)}

To evaluate the relations between the operating variables and the process responses (i.e., key performance indicators), nonlinear mathematical programming was conducted using the response surface methodology (RSM) based on the CCD method in this study. The RSM, first developed by Box and Wilson (1951), is a collection of statistical and mathematical techniques that are used for modeling and 
analysis of responses using non-linear regression. In this study, factors including applied voltage (5.4813.81 V, coded as A) and feed flow rate $(410-840 \mathrm{~mL} / \mathrm{min}$, coded as B) were designated with low and high levels in D-optimal design, as shown in Table 2.

\section{$<$ Table 2>}

Two different response models (i.e., output variable) including productivity $(\varphi)$ and energy consumption $\left(\psi_{c}\right)$ were established using RSM. Least-squares estimation was used to determine the model parameters in the approximating polynomial equation. According to the analysis of variance table, the developed response models were all significant because the p-value were less than 0.05 with acceptable $\mathrm{R}^{2}$ values. In general, any values of "Prob $>$ F" less than 0.05 indicate that model terms are significant, while values greater than 0.100 indicate that the model terms are not significant.

\subsection{Analytical methods}

The conductivity of samples was measured with a conductivity meter (SevenGo, Mettler Toledo). Chloride was analyzed by ion chromatograph (IC, Metrohm IC Plus system) with a Grace (Deerfield, IL) Allsep anion column and a conductivity detector. A flow rate of $1 \mathrm{~mL} / \mathrm{min}$ with a mobile phase of $4.2 \mathrm{mM}$ carbonate and $100 \mathrm{mM}$ sulfuric acid $\left(\mathrm{H}_{2} \mathrm{SO}_{4}\right)$ as the suppressor liquid was used. A calibration curve between ionic conductivity and chloride concentration was established. Selected chloride concentrations were re-measured with the IC equipment.

\section{Results and Discussion}

\subsection{Effect of different operating conditions on removal ratio}

The effect of treatment time, applied voltage and feed flow rate on both removal ratio and current 
efficiency was evaluated. Fig. 2(a) shows the effect of applied voltage and treatment time on the salt removal ratio. In the batch experiments, the removal ratio of salt in solution continuously increased with time. In all cases, greater than $99 \%$ salt removal can be achieved at 120 mins at various applied voltages. The salt removal ratio (or the rate of ion transport) steadily (linearly) increased as the applied cell voltage (i.e., voltage drop per cell pair) increased from $1.37 \mathrm{~V}$ to $3.15 \mathrm{~V}$. This is attributed to the fact that the mass transfer rate of charged ions in bulk solution did not reach concentration polarization at the operating voltages in the resin bed. In other words, the adsorption/desorption of ions in the resin beads is not the rate limiting step. Therefore, the resin bed enhanced the overall conductivity in the dilute compartment.

\section{$<$ Figure 2 $>$}

With an applied voltage per cell pair of $3.45 \mathrm{~V}$, the salt removal ratio in effluent stream at 30 min was greater than $95 \%$, with an outflow concentration of approximately $0.2 \mathrm{~g} / \mathrm{L} \mathrm{NaCl}$. When the cell voltage exceeded $3.15 \mathrm{~V}$, the rate of ion transport (i.e., $-\mathrm{dC} / \mathrm{dt}$ ) was plateaued, indicating that excess voltage resulted in water splitting. At high applied cell voltage, water splitting reaction may occur at two locations: (1) the ion-exchange membrane surface, i.e., on both sides of ion-exchange membranes, and (2) the surface of cation and anion-exchange resin beads (Keramati et al., 2010). The former reduces ion transfer through the CEM and AEM. The later helps regenerate the ion-exchange resin beads. The fraction of water splitting at each location is dependent on applied electric field, ion concentrations, ion mobility in liquid and ionexchange resin, feed flow rate, composition of cation and anion resin beads. When excess voltage is applied, a portion of the electricity is consumed for proton and hydroxide generation and recombination, thereby reducing energy efficiency (defined in Eq (4)). The applied electric field, such as voltage (or current), should be carefully controlled to avoid excess water splitting, where the optimization of applied voltage are presented in Section 3.5.

Fig. 2(b) presents the effect of feed flow rate on the salt removal ratio. Increase of feed flow rate from 
$410 \mathrm{~mL} / \mathrm{min}$ to $840 \mathrm{~mL} / \mathrm{min}$ had a minor effect on $\mathrm{NaCl}$ removal. This is attributed to high current utilization, which is defined as the fraction of applied current to completely remove the charged ions from the feed solution. Current utilization is proportional to the feed flow rate, feed concentration and number of charges; while inversely proportional to applied current. In the batch operation, current utilization is normally greater than $100 \%$ because it could typically operate at a high feed flow rate. In other words, initially, the applied current is almost completely utilized for transporting charged ions from the feed solution through membrane.

As time elapses, concentration of the feed stream is reduced, leading to a continuous decrease in current utilization. Once current utilization drops below 100\%, applied current is also used for water splitting. The rate of ion transport from the dilute stream to the resin (i.e., $-\mathrm{dC} / \mathrm{dt}$ ) is influenced by the feed flow rate, where it reached a maximal rate when the flow rate increased from $410 \mathrm{~mL} / \mathrm{min}$ to 625 $\mathrm{mL} / \mathrm{min}$. Further increase in feed flow rate beyond $625 \mathrm{~mL} / \mathrm{min}$ will result in a significant reduction of ion transport rate. This could be due to limitation in ion adsorption/desorption on the resin beads. Excessive flow rate reduces adsorption/desorption rate of ions from the liquid to the resin, therefore, reducing the removal rate. Thus the optimal feed flow rate is a balance between productivity and energy consumption.

\subsection{Effect of voltage and feed flow rate on current efficiency}

Fig. 3 illustrates the relationship between the feed $\mathrm{NaCl}$ concentration and the current efficiency under different conditions. Current efficiency generally decreased with decrease of the feed flow concentration. Decreasing ion concentration is similar to an increase in resistance of bulk solution; therefore, a higher voltage should be applied to maintain the same level of current flow across the stack, where excess electrical energy results in water splitting. Similar trends were observed even under a range of operating 
conditions. Based on the slope of the correlation curve, the feed concentration can be typically divided into three zones. Zone A represents an appropriate operating window of feed concentration $(1.8-5 \mathrm{~g} / \mathrm{L})$ for the high current efficiency greater than $50 \%$. In this zone, due to a sufficient ion conductivity across the EDI stack, most of the applied electric energy is efficiently utilized in ion transport of salt. In contrast, within a lower feed concentration range of $0.6-1.8 \mathrm{~g} / \mathrm{L}$ (Zone B), the current efficiency was found to be dramatically reduced from $50 \%$ to $35 \%$. A further decrease in feed flow concentration to less than $0.6 \mathrm{~g} / \mathrm{L}$ (Zone C) would increase the resistance of ion transport and voltage difference across the stack, thereby resulting in rapid decrease in the current efficiency.

\section{$<$ Figure 3 $>$}

The significant increase in cell voltage would induce a great fraction of water splitting reaction. The fraction of water splitting at each location is dependent on applied electric field, ion concentrations, ion mobility in liquid and ion-exchange resin, feed flow rate, composition of cation and anion resin beads. As the previous discussion, when excess voltage is applied, a portion of the electricity is consumed for proton and hydroxide generation and recombination, reducing energy efficiency. In addition, in current evaluation, part of the applied voltage was used for the electrode reactions in cathodic and anodic compartments, which was much greater than the voltage across each call pair. For instance, in the case of applied voltage at $6.72 \mathrm{~V}$ in 4 cell-pair RW-EDI operation, the actual measured cell voltage drops crossing all the cell pairs was only $2.22 \mathrm{~V}$ (or $0.56 \mathrm{~V} /$ cell). In other words, approximate $68 \%$ of applied voltage was used in the electrode reactions. In commercial-scale stack of multiple cell-pair ED or EDI operation (such as 100 cell-pairs), the percentage of voltage used in the electrode reactions will be less than $8 \%$. It thus suggests that the applied voltages need to be adjusted to match ion concentration, thereby reducing water splitting and increasing current efficiency. 


\subsection{Development of kinetic model for RW-EDI desalination}

The removal kinetics of $\mathrm{NaCl}$ from the brackish water is impacted by both the applied voltage and feed flow rate (or superficial velocity). We chose the first-order kinetic model to correlate the performance of $\mathrm{NaCl}$ removal under different operating conditions with RW-EDI, which can be represented by Eq. (5):

$$
-\frac{d C}{d t}=k C
$$

where $k$ is the apparent rate constant, and $C$ is the concentration within the feed compartment at any time

(g/L). Table 3 presents the results of kinetic modelling under different operating conditions, which indicate that the experimental data fit the first-order model quite well.

\section{$<$ Table 3>}

The relative percent differences of removal ratio between experimental data and values predicted by the obtained model were less than 10\%, as shown in Fig. 4. As the aforementioned findings, the initial removal rate is greater due to the higher concentration difference under electric-field driving force. As time elapsed, the removal rate decreases with the decrease in solution conductivity, thereby limiting charge transport. Greater removal rates were observed at higher voltages. For example, the rate constant $(k)$ was $0.0971 \pm 0.0037 \mathrm{~min}^{-1}$ with an applied voltage of $3.15 \mathrm{~V}$ per cell at a feed flow rate of $775 \mathrm{~mL} / \mathrm{min}$.

\section{$<$ Figure 4>}

Rate constants were correlated with the operating parameters, as shown in Eq. (6):

$$
k=f\left(v_{s}, U\right)
$$

Where $v_{s}$ is the superficial velocity $(\mathrm{cm} / \mathrm{s})$, and $U$ is the applied voltage per cell pair $(\mathrm{V})$. These two factors 
were correlated with the rate constant in a power function. For example, Fig. 5 reveals the relationship between the rate constant and applied voltage.

\section{$<$ Figure 5 $>$}

The power function of applied voltage is well correlated to the rate constant, with an $\mathrm{R}^{2}$ value of 0.954 . Similar analysis was conducted for the superficial velocity. The relationship of rate constant with applied voltage and superficial velocity can be correlated by Eq. (7):

$$
k=0.020 \times v_{s}^{0.028} \times U^{1.284}
$$

where the ranges of the superficial velocity and voltage per cell pair in this correlation are

$$
\begin{aligned}
& 1.43<v_{s}<2.91 \\
& 1.37<U<3.45
\end{aligned}
$$

A comparison of experimental data with the kinetic model indicates that the relative percent difference between rate constants from experimental data and obtained kinetic models were less than 10\% (Fig. 6). The dependence of applied voltage on rate constant was much greater than that of superficial velocity because the rate constants varied with both the applied voltage and superficial velocity to the 1.28 and 0.03 power, respectively [Eq. (7)]. Increasing cell voltage enhances removal kinetics more than the feed flow rate. However, applied voltage is also strongly related to energy consumption. Therefore, the applied voltage should be adjusted to a minimal level to achieve targeted effluent water quality requirements at a desired retention time, as well as to reduce energy consumption.

\section{$<$ Figure 6>}




\subsection{Balancing process productivity and energy consumption by response surface models}

In this study, two response surface models on productivity and energy consumption were established using the RSM according to the experimental data. The coded models associated with applied voltage $(A)$ and feed flow rate $(B)$ on productivity $\left(\varphi, \mathrm{L} / \mathrm{hr} / \mathrm{m}^{2}\right)$ and energy consumption $\left(\psi_{c}, \mathrm{kWh} / \mathrm{m}^{3}\right)$ are presented in Eqs. (10) and (11), respectively. Figs. 7(a) and 7(b) show the comparison of actual and predicted values

for productivity $(\varphi)$ and energy consumption $\left(\psi_{c}\right)$, respectively. The results indicated that the developed surface model exhibited a satisfactory estimation of the actual response value. In other words, the analysis of the response surface was representatively equivalent to the analysis of the experimental system.

$$
\begin{aligned}
& \varphi(\text { coded })=53.0+20.6 * \mathrm{~A}-1.32 * \mathrm{~B}-4.32 * \mathrm{~A} * \mathrm{~B}+1.17 * \mathrm{~A}^{2}-2.50 * \mathrm{~B}^{2}+4.77 * \mathrm{~A}^{2} \mathrm{~B} \\
& \psi_{c}(\text { coded })=1.64+0.7 * \mathrm{~A}-0.11 * \mathrm{~B}
\end{aligned}
$$

$<$ Figure 7 $>$

There were dependent relationships between applied voltage and feed flow rate on the productivity, while the applied voltage and feed flow rate were independent to each other on the energy consumption (i.e., linear model). Fig. 8 shows the contour and 3D response surface plots of these established mathematical models. Changing the operating factor values impacts the response on the contour or 3D plots. From the RSM results, productivity was found to be well fit in a modified cubic model, which was influenced interactively by both applied voltage and feed flow rate. However, the energy consumption $(\psi)$ can be well expressed by a linear model, revealing that it increases directly with the increase in applied voltage while decreasing with increase in feed flow rate. Energy consumption was found to be more sensitive to the applied voltage (with a coefficient of 0.7) than feed flow rate (with a coefficient of 0.1).

\section{$<$ Figure 8 $>$}


A cost-effective process for impaired water desalination requires a high process productivity (small land footprint), at the same time, achieving low energy consumption (low operating cost). In this study, the relationship between productivity and energy consumption was experimentally evaluated under an initial $\mathrm{NaCl}$ feed concentration of $5 \mathrm{~g} / \mathrm{L}$. To balance productivity $(\varphi)$ and energy consumption $\left(\psi_{c}\right)$ at a selected removal ratio target, the developed response surface models were utilized for identifying desired technological criteria. A removal ratio $\left(\eta_{r}\right)$ target of $90 \%$ was set to meet the effluent water quality requirement of less than $0.5 \mathrm{~g} / \mathrm{L} \mathrm{NaCl}$, as expressed in Eq. (12). In this case, the design objectives were to maximize the productivity; while minimizing the energy consumption, as expressed in Eqs. (13) and (14), respectively:

Constraint: $\eta_{r}=f(\mathrm{~A}, \mathrm{~B})>90 \%$

Max. (productivity): $\varphi=f(\mathrm{~A}, \mathrm{~B})>37.85 \mathrm{~L} / \mathrm{hr} / \mathrm{m}^{2}$ (i.e., $\sim 10 \mathrm{gal} / \mathrm{hr} / \mathrm{m}^{2}$ )

Min. (energy consumption): $\psi_{c}=f(\mathrm{~A}, \mathrm{~B})<0.9 \mathrm{kWh} / \mathrm{m}^{3}$

With the constraint on removal performance and objectives for each targeted response, the potential ranges of the operating factor designs could be identified graphically by creating an overlay contour that highlights an area of operability. Fig. 9 shows the results of multi-objective evaluation for RW-EDI from the non-linear programming analysis. The ideal operating conditions should be at an applied voltage of $1.73 \mathrm{~V}$ per cell pair with a feed flow rate of $775 \mathrm{~mL} / \mathrm{min}$, corresponding to a productivity of $39.4 \mathrm{~L} / \mathrm{hr} / \mathrm{m}^{2}$ (i.e., $\sim 10.4 \mathrm{gal} / \mathrm{hr} / \mathrm{m}^{2}$ ) at energy consumption of $0.887 \mathrm{kWh} / \mathrm{m}^{3}$. In this case, the outflow TDS concentration of the feed stream from the RW-EDI would be $0.5 \mathrm{~g} / \mathrm{L}$, corresponding to a removal efficiency of $90 \%$. In comparison to RO, the best achievable energy consumption for treating feed water concentration greater than $5 \mathrm{~g} / \mathrm{L} \mathrm{NaCl}$ in large-scale RO plants was $1.2-1.5 \mathrm{kWh} / \mathrm{m}^{3}$ (Zhao et al., 2013), corresponding to energy efficiency of $10-12 \%$ (assumed $50 \%$ recovery). It thus suggests that RW-EDI is 
more energy-efficient than RO for impaired water desalination.

\section{$<$ Figure 9 $>$}

\subsection{Economic evaluation of impaired water desalination}

Desalination of impaired water, such as cooling and process water, using EDI offers the potential for an abundant source of fresh water. Continuous EDI has been applied on an industrial scale as a cost effective alternative to provide deionized water and/or ultrapure water of extremely low conductivity (Grabowski et al., 2006). Although RO is the dominant desalination process for seawater in the United States, it is nearing the practical limits for brackish water desalination in terms of energy efficiency (Carter, 2015; USDOE, 2014). Instead of using RO, the effectiveness of using RW-EDI for impaired water desalination include (i) a reduction in energy consumption, (ii) an increase in clean water throughput, and (ii) less amounts of concentrate brine which require subsequent treatments. Therefore, RW-EDI (i.e., advanced EDI process) should be viewed as a crucial component in the portfolio of water supply options, especially for the reclamation of impaired water.

Typically, the major costs of a desalination plant such as RO, ED and RW-EDI include (i) capital cost, (ii) processing and operating costs, and (iii) maintenance costs, e.g., periodical replacement of membrane. Using RO in purifying impaired water, the processing costs would be influenced greatly by the size of the RO plant, typically in the range of USD $0.42-1.20$ per $\mathrm{m}^{3}$ fresh water production. In the case of conventional ED, the operating costs were estimated to be USD 0.73 per $\mathrm{m}^{3}$ fresh water production based on a treatment capacity of $4000 \mathrm{~m}^{3} / \mathrm{d}$ (Yen et al., 2017). In comparison, using RW-EDI in purifying brackish water, the system size exhibits a minor effect on the processing cost due to its nearly linear scaleup of electric driving forces, where the processing costs are estimated in the range of USD $0.35-0.45$ per $\mathrm{m}^{3}$ fresh water production according to the bench-scale operations in this study. Additionally, the average 
service life of the IEX membranes used in ED/EDI is about 10 years, which is $2-3$ times longer than the porous membranes used in RO (Wright and Winter, 2014).

Thermoelectric power plants present challenges in reduction of freshwater consumption and ensure of water quality (especially salinity and temperatures) since they withdraw a huge amount of freshwater for cooling during power generation. One major approaches to reduce freshwater consumption at thermoelectric plants is water reclamation from in-plant operations. In the United States, thermoelectric power generation withdraws approximately 40\% of freshwater for cooling, i.e., 196 billion gallons per day in 2011 (USDOE, 2014). By considering the best achievable performance of RO for brackish water desalination, i.e., $1.2 \mathrm{kWh} / \mathrm{m}^{3}$ (Zhao et al., 2013), the energy consumption for reclaiming cooling water at thermoelectric plants in U.S. would be about $890.2 \mathrm{GWh}$ per day. If the current-state RW-EDI was applied for cooling water reclamation instead, i.e., $0.657 \mathrm{kWh} / \mathrm{m}^{3}$, a huge amount of $\sim 402.8 \mathrm{GWh} /$ day energy can be saved. This is equivalent to a daily saving on electricity bill about 27.8 million USD, assuming the average electricity price for industrial use at 0.069 USD per kWh in 2015 (IEA, 2016). Similarly, assumed average monthly electricity consumption for a residential utility customer in the U.S. was $909 \mathrm{kWh}$ (USEIA, 2015), the saved energy is able to supply for energy usage in $\sim 13.5$ million households.

\section{Conclusions}

The effect of applied voltage and feed flow rate on the salt removal ratio, current efficiency, productivity, and energy consumption was evaluated for RW-EDI using kinetic and response surface models. The salt removal ratio increases with time, and greater than $99 \%$ removal ratio can be achieved at 120 mins. Due to batch mode operation, the increase in feed flow rate from $410 \mathrm{~mL} / \mathrm{min}$ to $840 \mathrm{~mL} / \mathrm{min}$ did not impact salt removal. In contrast, the feed flow rate plays a more significant role on current efficiency than applied voltage affecting energy consumption and productivity. Kinetic rate constants vary in a power function with applied voltage and superficial velocity to 1.28 and 0.03 power, respectively. It 
thus suggests that determination of the appropriate voltages is critical to meet effluent water quality requirements at a desired retention time while minimizing energy consumption. Furthermore, results indicate that RW-EDI should be competitive with commercial RO for brackish water desalination, in terms of energy efficiency and productivity. In the case of cooling water reclamation at thermoelectric plants in U.S., a huge amount of energy (i.e., $\sim 400 \mathrm{GWh} /$ day) can be saved if deploying RW-EDI for cooling water desalination, instead of using commercial RO. The aforementioned energy could supply the energy usage for approximately 13.5 million households in the US, or be equivalent to a daily saving on electricity bill about 27.8 million USD. Future research will be focused on the impact of operating conditions on largescale continuous operations and the understanding of the removal mechanism using integrated mathematical models, as well as the cost benefit analysis and techno-economic analysis.

\section{Acknowledgements}

The submitted manuscript has been created by UChicago Argonne, LLC, Operator of Argonne National Laboratory (“Argonne”). Argonne, a US Department of Energy Office of Science laboratory, is operated under contract no. DE-AC02-06CH11357. The US Government retains for itself, and others acting on its behalf, a paid-up nonexclusive, irrevocable worldwide license in said article to reproduce, prepare derivative works, distribute copies to the public, and perform publicly and display publicly, by or

on behalf of the government. In addition, high appreciation goes to the Ministry of Science and Technology (MOST) of Taiwan (R.O.C.) under Grant Number MOST 106-3113-E-007-002 and 1042911-I-002-576 for the financial support.

\section{References}

AlMarzooqi, F.A., Al Ghaferi, A.A., Saadat, I., Hilal, N., 2014. Application of Capacitive Deionisation in water desalination: A review. Desalination 342, 3-15.

Alvarado, L., Chen, A., 2014. Electrodeionization: Principles, Strategies and Applications. Electrochim 
Acta 132, 583-597.

Arora, M.B., Hestekin, J.A., Snyder, S.W., St Martin, E.J., Lin, Y.J., Donnelly, M.I., Millard, C.S., 2007. The Separative Bioreactor: A Continuous Separation Process for the Simultaneous Production and Direct Capture of Organic Acids. Sep Sci Technol 42, 2519-2538.

Bian, Y., Yang, X., Liang, P., Jiang, Y., Zhang, C., Huang, X., 2015. Enhanced desalination performance of membrane capacitive deionization cells by packing the flow chamber with granular activated carbon. Water research 85, 371-376.

Biesheuvel, P.M., Bazant, M.Z., 2010. Nonlinear dynamics of capacitive charging and desalination by porous electrodes. Phys Rev E Stat Nonlin Soft Matter Phys 81, 031502.

Box, G.E.P., Wilson, K.B., 1951. On the experimental designs for exploring response surfaces. Ann. Math. Stat. 13, 1-45.

Carter, N.T., 2015. Desalination and Membrane Technologies: Federal Research and Adoption Issues. Congressional Research Service, Washington, DC, p. 18.

Datta, S., Henry, M.P., Lin, Y.J., Fracaro, A.T., Millard, C.S., Snyder, S.W., Stiles, R.L., Shah, J., Yuan, J., Wesoloski, L., Dorner, R.W., Carlson, W.M., 2013a. Electrochemical CO2Capture Using ResinWafer Electrodeionization. Ind Eng Chem Res 52, 15177-15186.

Datta, S., Lin, Y.J., Schell, D.J., Millard, C.S., Ahmad, S.F., Henry, M.P., Gillenwater, P., Fracaro, A.T., Moradia, A., Gwarnicki, Z.P., Snyder, S.W., 2013b. Removal of Acidic Impurities from Corn Stover Hydrolysate Liquor by Resin Wafer Based Electrodeionization. Ind Eng Chem Res 52, 13777-13784.

Datta, S., Lin, Y.P., Snyder, S.W., 2014. Current and emerging separations technologies in biorefining, Advances in biorefineries. Woodhead Publishing, Cambridge, UK, pp. 112-151.

Dlugolecki, P., van der Wal, A., 2013. Energy recovery in membrane capacitive deionization. Environ Sci Technol 47, 4904-4910.

Drioli, E., Ali, A., Macedonio, F., 2015. Membrane distillation: Recent developments and perspectives. Desalination 356, 56-84.

Elimelech, M., Phillip, W.A., 2011. The future of seawater desalination: energy, technology, and the environment. Science 333, 712-717.

Feng, X., Wu, Z., Chen, X., 2007. Removal of metal ions from electroplating effluent by EDI process and recycle of purified water. Sep Purif Technol 57, 257-263.

Gill, J., 2010. A synergistic combination of advanced separation and chemical scale inhibitor technologies for efficient use of impaired water as cooling water in coal-based power plants. US DOE, Oak Ridge, 
TN, p. 36.

Grabowski, A., Zhang, G., Strathmann, H., Eigenberger, G., 2006. The production of high purity water by continuous electrodeionization with bipolar membranes: Influence of the anion-exchange membrane permselectivity. Journal of Membrane Science 281, 297-306.

Gurram, R.N., Datta, S., Lin, Y.J., Snyder, S.W., Menkhaus, T.J., 2011. Removal of enzymatic and fermentation inhibitory compounds from biomass slurries for enhanced biorefinery process efficiencies. Bioresour Technol 102, 7850-7859.

IEA, 2016. Electricity Information 2016. OECD/IEA (International Energy Agency), France, p. 650.

Keramati, N., Moheb, A., Ehsani, M.R., 2010. Effect of operating parameters on NaOH recovery from waste stream of Merox tower using membrane systems: Electrodialysis and electrodeionization processes. Desalination 259, 97-102.

Lin, Y.P.J., Henry, M.P., W., S.S., 2008. Electronically and ionically conductive porous material and method for manufacture of resin wafers therefrom, in: U.S. Patent No. 7977395 (Ed.). Uchicago Argonne, LLC, U.S.A.

Lopez, A.M., Hestekin, J.A., 2015. Improved organic acid purification through wafer enhanced electrodeionization utilizing ionic liquids. J Membr Sci 493, 200-205.

Lopez, A.M., Williams, M., Paiva, M., Demydov, D., Do, T.D., Fairey, J.L., Lin, Y.J., Hestekin, J.A., 2017. Potential of electrodialytic techniques in brackish desalination and recovery of industrial process water for reuse. Desalination 409, 108-114.

Lu, H., Wang, Y., Wang, J., 2015. Recovery of Ni2+ and pure water from electroplating rinse wastewater by an integrated two-stage electrodeionization process. Journal of Cleaner Production 92, 257-266.

Luo, H., Wang, Q., Zhang, T.C., Tao, T., Zhou, A., Chen, L., Bie, X., 2014. A review on the recovery methods of draw solutes in forward osmosis. J Water Process Eng 4, 212-223.

Montgomery, D.C., 2017. Design and Analysis of Experiments, ninth ed. John Wiley \& Sons, Inc.

OECD/IEA, 2013. Water for Energy: Is energy becoming a thirstier resource, World Energy Outlook 2012. International Energy Agency, France, p. 33.

Pan, S.Y., Snyder, S.W., Ma, H.W., Lin, Y.J., Chiang, P.C., 2017. Development of a Resin Wafer Electrodeionization Process for Impaired Water Desalination with High Energy Efficiency and Productivity. Acs Sustainable Chemistry \& Engineering 5, 2942-2948.

Porada, S., Zhao, R., van der Wal, A., Presser, V., Biesheuvel, P.M., 2013. Review on the science and technology of water desalination by capacitive deionization. Prog Mater Sci 58, 1388-1442. 
Sahin, O., Stewart, R.A., Porter, M.G., 2015. Water security through scarcity pricing and reverse osmosis: a system dynamics approach. Journal of Cleaner Production 88, 160-171.

Sharqawy, M.H., Zubair, S.M., Lienhard, J.H., 2011. Second law analysis of reverse osmosis desalination plants: An alternative design using pressure retarded osmosis. Energy 36, 6617-6626.

USDOE, 2014. The Water-Energy Nexus: Challenges and Opportunities. U.S. Department of Energy, USA, p. 262.

USEIA, 2015. Commercial average monthly bill by Census Division, and State, in: Administration, U.S.E.I. (Ed.), Washington, DC.

Welgemoed, T.J., Schutte, C.F., 2005. Capacitive Deionization Technology ${ }^{\mathrm{TM}}$ : An alternative desalination solution. Desalination 183, 327-340.

Wright, N.C., Winter, A.G., 2014. Justification for community-scale photovoltaic-powered electrodialysis desalination systems for inland rural villages in India. Desalination 352, 82-91.

Xu, W., Chen, Q., Ge, Q., 2017. Recent advances in forward osmosis (FO) membrane: Chemical modifications on membranes for FO processes. Desalination 419, 101-116.

Yen, F.C., You, S.J., Chang, T.C., 2017. Performance of electrodialysis reversal and reverse osmosis for reclaiming wastewater from high-tech industrial parks in Taiwan: A pilot-scale study. J Environ Manage 187, 393-400.

Zhang, Y., Wang, L., Xuan, S., Lin, X., Luo, X., 2014. Variable effects on electrodeionization for removal of Cs+ ions from simulated wastewater. Desalination 344, 212-218.

Zhao, R., Porada, S., Biesheuvel, P.M., van der Wal, A., 2013. Energy consumption in membrane capacitive deionization for different water recoveries and flow rates, and comparison with reverse osmosis. Desalination 330, 35-41. 
Table 1. Specification of Resin Wafer Electrodeionization (RW-EDI) System Used in This Study.

\begin{tabular}{|c|c|c|c|}
\hline \multicolumn{2}{|c|}{ Specifications } & \multirow{2}{*}{$\begin{array}{l}\text { Unit } \\
-\end{array}$} & \multirow{2}{*}{$\begin{array}{l}\text { Specification } \\
\text { batch }\end{array}$} \\
\hline EDI stack & Operating modulus & & \\
\hline & Cell pair & - & 4 \\
\hline \multirow[t]{5}{*}{ Resin wafer } & Cation exchange resin & - & Purolite PFC100E \\
\hline & Anion exchange resin & - & Purolite PFA444 \\
\hline & Length & $\mathrm{cm}$ & 17.6 \\
\hline & Width & $\mathrm{cm}$ & 11.1 \\
\hline & Thickness & $\mathrm{cm}$ & $0.5-1.0$ \\
\hline \multirow[t]{4}{*}{ Membranes } & Cation exchange membrane ${ }^{a}$ & - & Neosepta CMX, strong acid cation \\
\hline & Anion exchange membrane ${ }^{a}$ & - & Neosepta AMX, strong basic cation \\
\hline & Bipolar membrane ${ }^{a}$ & - & Neosepta BP, thickness $0.22 \mathrm{~mm}$ \\
\hline & Cross surface area & $\mathrm{cm}^{2}$ & 195 \\
\hline \multirow{6}{*}{$\begin{array}{l}\text { Water } \\
\text { samples } \\
\text { and } \\
\text { solutions }\end{array}$} & Synthesis brackish water (feed) & $\mathrm{g} / \mathrm{L} \mathrm{NaCl}$-eq & 5.0 \\
\hline & Feed volume & $\mathrm{L}$ & 2 \\
\hline & Concentrate stream & $\mathrm{g} / \mathrm{L} \mathrm{NaCl-eq}$ & $5.84(\sim 0.1 \mathrm{~N})$ \\
\hline & Concentrate flow rate & $\mathrm{mL} / \mathrm{min}$ & 1100 \\
\hline & Concentrate volume & $\mathrm{L}$ & 2 \\
\hline & Electrode rinse & - & $2.5 \% \mathrm{Na}_{2} \mathrm{SO}_{4}$ \\
\hline
\end{tabular}

a. Membranes were purchased from Ameridia. 
Table 2. Two Factors with Five Levels using Central Composite Design (CCD) Method.

\begin{tabular}{lllllllll}
\hline \multirow{2}{*}{ Factors } & \multirow{2}{*}{ Properties } & \multirow{2}{*}{ Units } & \multicolumn{2}{l}{ Set values } & \multicolumn{2}{l}{ Coded (actual) values } & \multicolumn{2}{l}{ Statistics } \\
\cline { 4 - 9 } & & & Min. & Max. & Min. & Max. & Mean & Std. Dev. \\
\hline A & Applied voltage & $\mathrm{V}$ & 5.48 & 13.81 & $-1(6.70)$ & $1(12.59)$ & 9.65 & 2.31 \\
$\mathrm{~B}$ & Feed flow rate & $\mathrm{mL} / \mathrm{min}$ & 410 & 840 & $-1(475)$ & $1(775)$ & 625 & 118 \\
\hline
\end{tabular}


Table 3. First-Order Kinetic Modelling under Different Operating Conditions for RW-EDI.

\begin{tabular}{lllllll}
\hline \multirow{2}{*}{ Run } & \multicolumn{2}{l}{ Operating conditions } & & Experiments & Kinetic model & \\
\cline { 2 - 6 } & Voltage & Voltage per & $\mathrm{Q}_{\mathrm{f}}$ & $\begin{array}{l}\text { Removal ratio } \\
(\%)^{\mathbf{a}}\end{array}$ & $\begin{array}{l}\text { Rate constant, first- } \\
\text { order }\left(\mathrm{min}^{-1}\right)\end{array}$ & $\mathrm{R}^{\mathbf{b}}$ \\
\hline 1 & $(\mathrm{~V})$ & cell $(\mathrm{V})$ & $(\mathrm{mL} / \mathrm{min})$ & $0.0261 \pm 0.0028$ & 0.978 \\
2 & 6.48 & 1.37 & 625 & 85.0 & $0.0385 \pm 0.0023$ & 0.994 \\
3 & 9.65 & 1.68 & 625 & 94.6 & $0.0636 \pm 0.0040$ & 0.995 \\
4 & 12.59 & 3.15 & 625 & 99.7 & $0.0885 \pm 0.0029$ & 0.999 \\
5 & 13.81 & 3.45 & 625 & 99.7 & $0.0965 \pm 0.0021$ & 1.000 \\
6 & 9.65 & 2.41 & 410 & 99.5 & $0.0687 \pm 0.0023$ & 0.999 \\
7 & 9.65 & 2.41 & 475 & 99.6 & $0.0643 \pm 0.0027$ & 0.998 \\
8 & 9.65 & 2.41 & 625 & 99.8 & $0.0709 \pm 0.0029$ & 0.998 \\
9 & 9.65 & 2.41 & 775 & 99.5 & $0.0611 \pm 0.0026$ & 0.998 \\
10 & 9.65 & 2.41 & 840 & 99.6 & $0.0605 \pm 0.0036$ & 0.995 \\
11 & 12.59 & 3.15 & 475 & 99.8 & $0.0878 \pm 0.0014$ & 1.000 \\
12 & 12.59 & 3.15 & 775 & 99.9 & $0.0971 \pm 0.0037$ & 0.999 \\
13 & 9.65 & 2.41 & 625 & 99.6 & $0.0658 \pm 0.0025$ & 0.998 \\
14 & 6.70 & 1.68 & 475 & 94.0 & $0.0363 \pm 0.0021$ & 0.994 \\
15 & 6.70 & 1.68 & 775 & 99.1 & $0.0510 \pm 0.0038$ & 0.992 \\
16 & 5.48 & 1.37 & 700 & 79.4 & $0.0249 \pm 0.0014$ & 0.993 \\
\hline
\end{tabular}

a. removal ratio at $60 \mathrm{~min} .{ }^{\mathbf{b}}$ : with $95 \%$ confidence intervals. 


\section{Figure Captions}

Fig. 1. Schematic diagram of resin wafer electrodeionization (RW-EDI) process for brackish water desalination. (1) dilute tank, (2) pump, (3) concentrate tank, (4) RW-EDI, (5) anode, (6) cathode, (7) feed stream, and (8) concentrate stream.

Fig. 2. Influence of (a) applied voltage (O: $1.37 \mathrm{~V} /$ cell, $\triangle: 1.68 \mathrm{~V} /$ cell, $\mathbf{\square}: 2.41 \mathrm{~V} /$ cell, $\diamond: 3.15 \mathrm{~V} /$ cell, $\nabla: 3.45 \mathrm{~V} /$ cell $)$ and (b) feed flow rate $(\bigcirc: 410 \mathrm{~mL} / \mathrm{min}, \triangle: 475 \mathrm{~mL} / \mathrm{min}, \boldsymbol{\square}: 625 \mathrm{~mL} / \mathrm{min}, \diamond$ : $775 \mathrm{~mL} / \mathrm{min}, \boldsymbol{\nabla}: 840 \mathrm{~mL} / \mathrm{min}$ ) on salt removal ratio under various treatment times (operating condition: initial concentration of $5 \mathrm{~g} / \mathrm{L} \mathrm{NaCl}$ ).

Fig. 3. Relationship of feed $\mathrm{NaCl}$ concentration and current efficiency (defined by Eq. (2)) under different conditions. $\mathrm{V}$ is the applied voltage across the four cell-pair EDI stack, and $\mathrm{Q}_{\mathrm{f}}$ is the feed flow rate.

Fig. 4. Comparison of experimental data in RW-EDI process with values predicted by kinetic model developed in this study

Fig. 5. Relationship of kinetic rate constant and applied voltage in terms of power function.

Fig. 6. Comparison of experimental data in RW-EDI process with values predicted by kinetic model developed in this study.

Fig. 7. Prediction vs. actual values of response surface model for (a) productivity and (b) energy consumption.

Fig. 8. (a) Contour plot and (b) 3D response surface for productivity; (c) contour plot and (d) 3D response surface for energy consumption.

Fig. 9. Multi-objective evaluation by non-linear programming analysis for balancing energy consumption and productivity of RW-EDI process. 
Fig. 1.

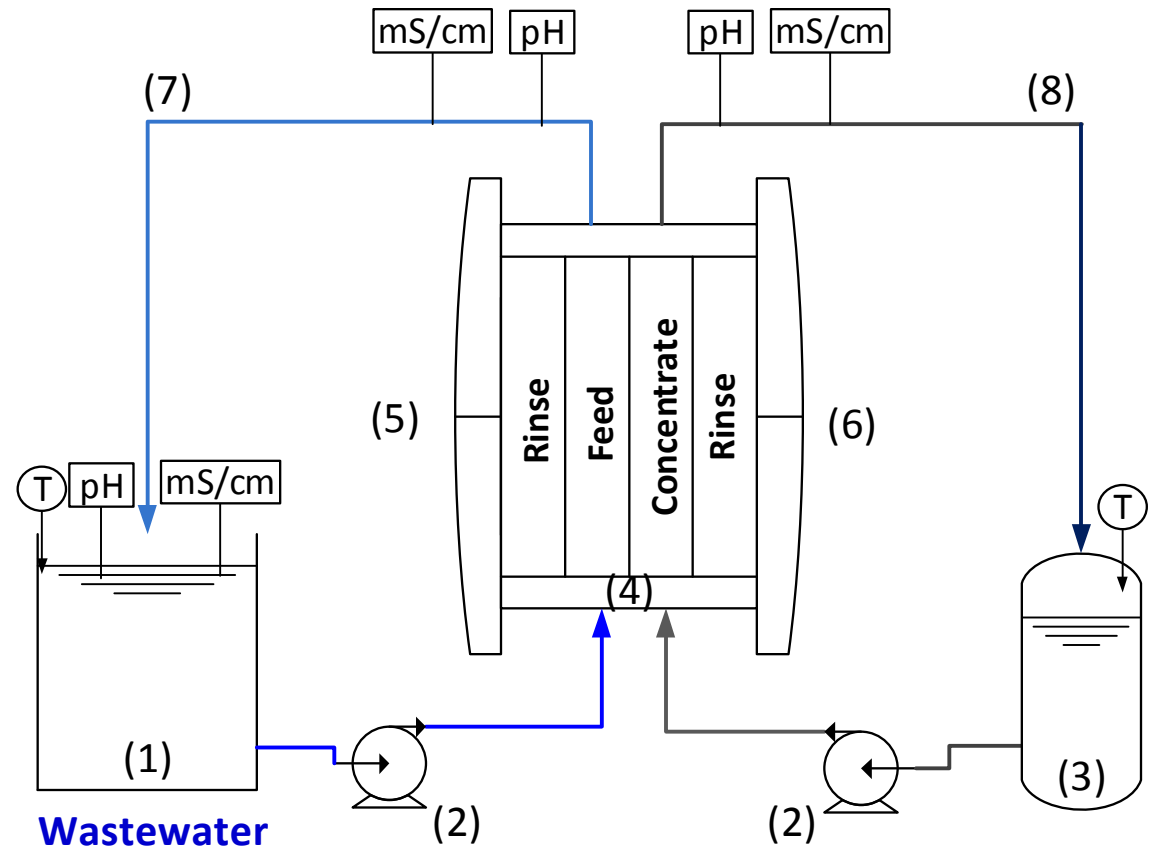


Fig. 2

(a)

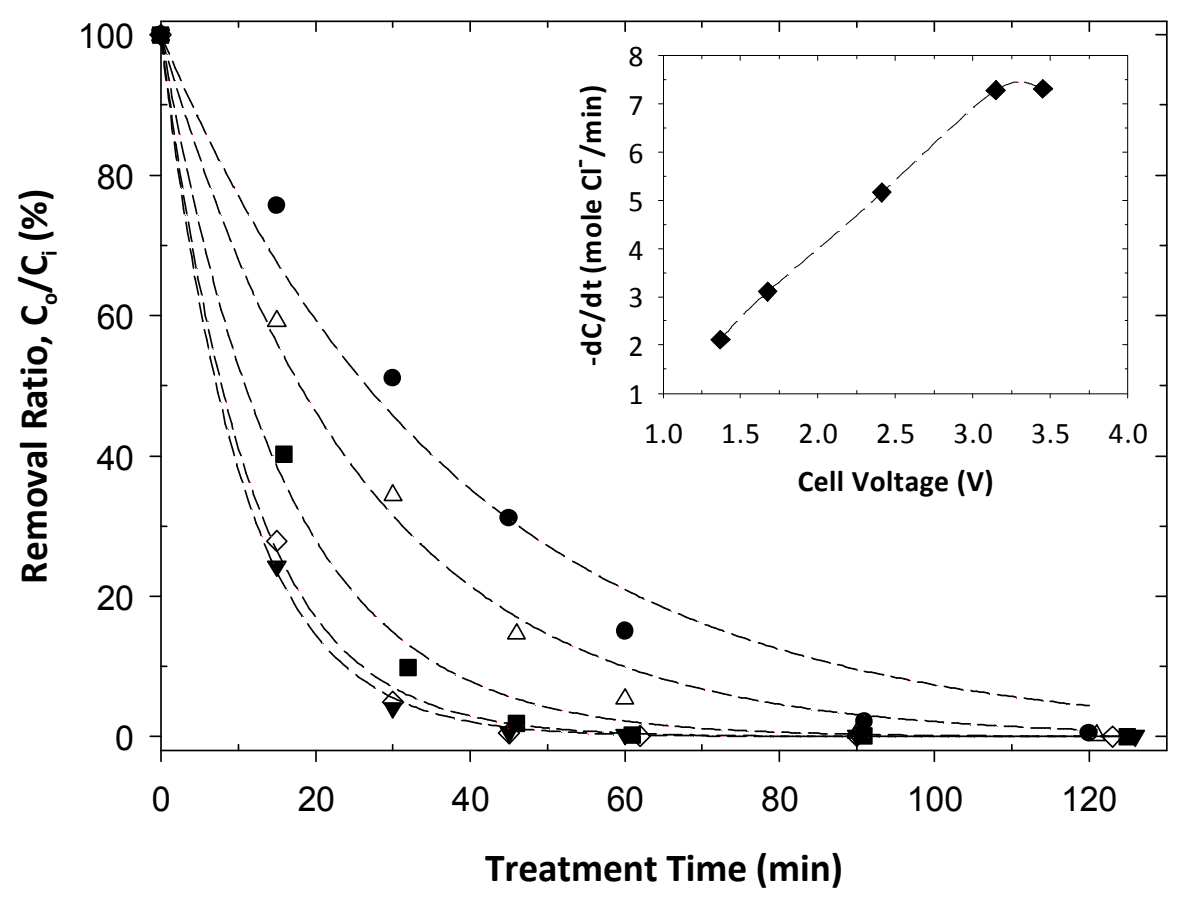

(b)

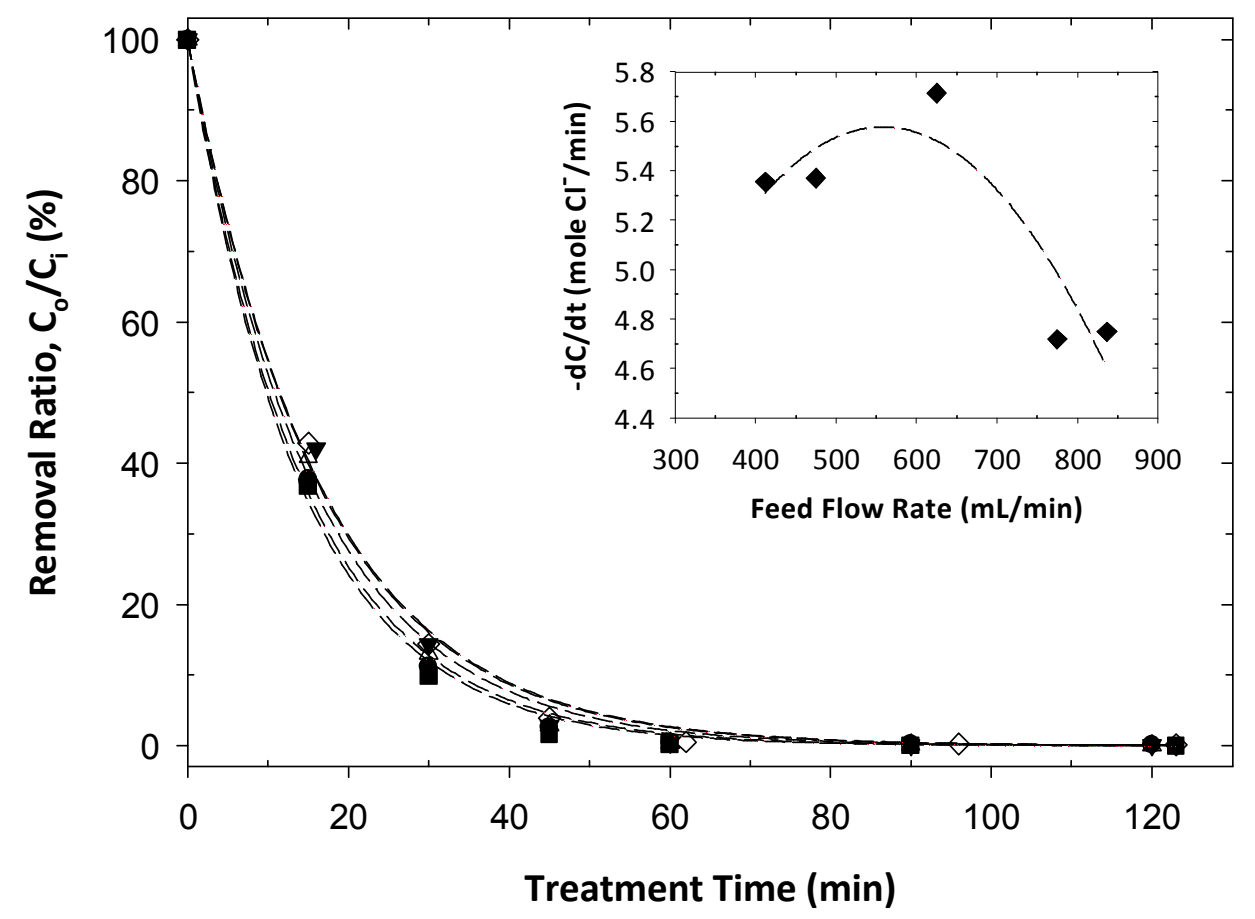


Fig. 3.

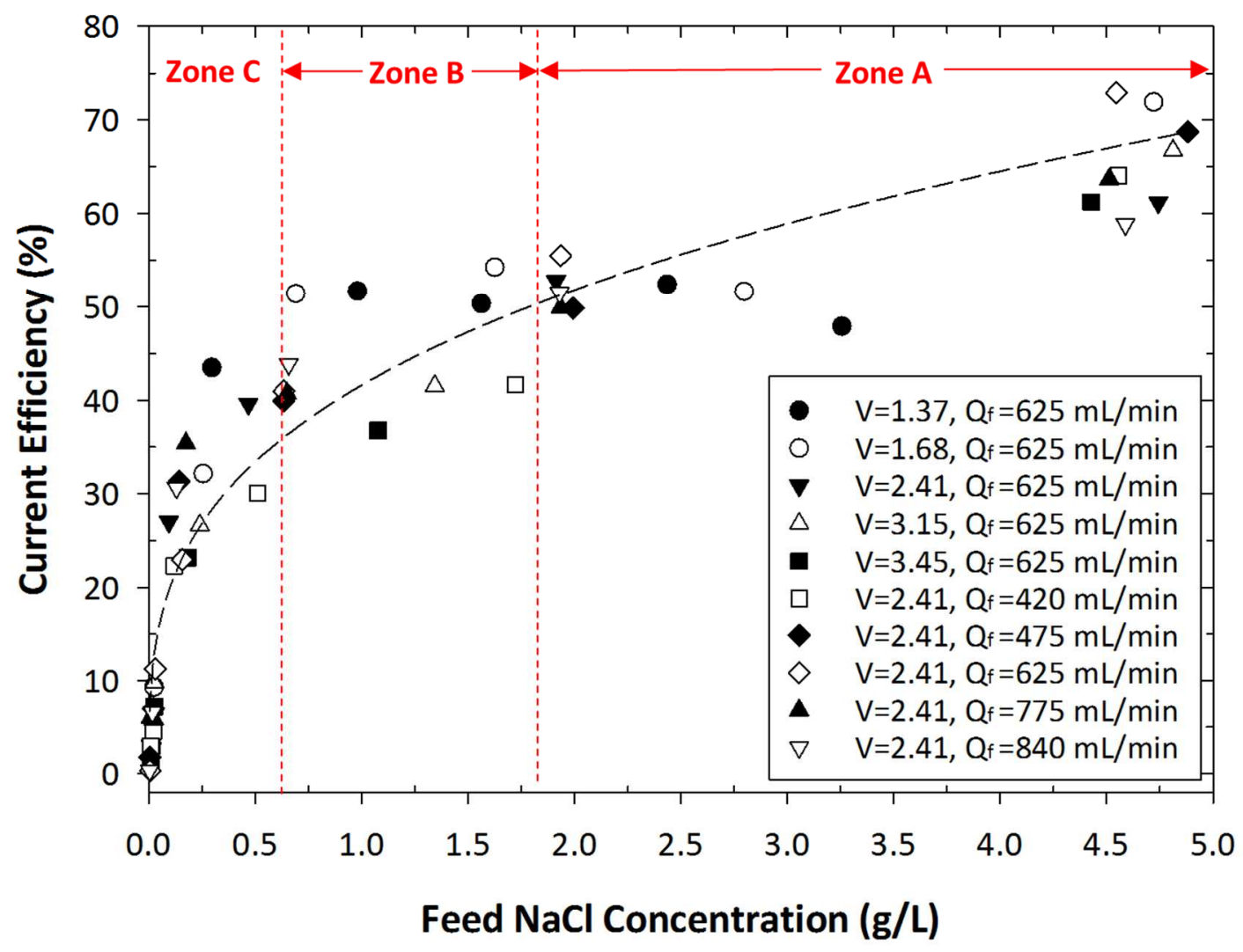


Fig. 4.

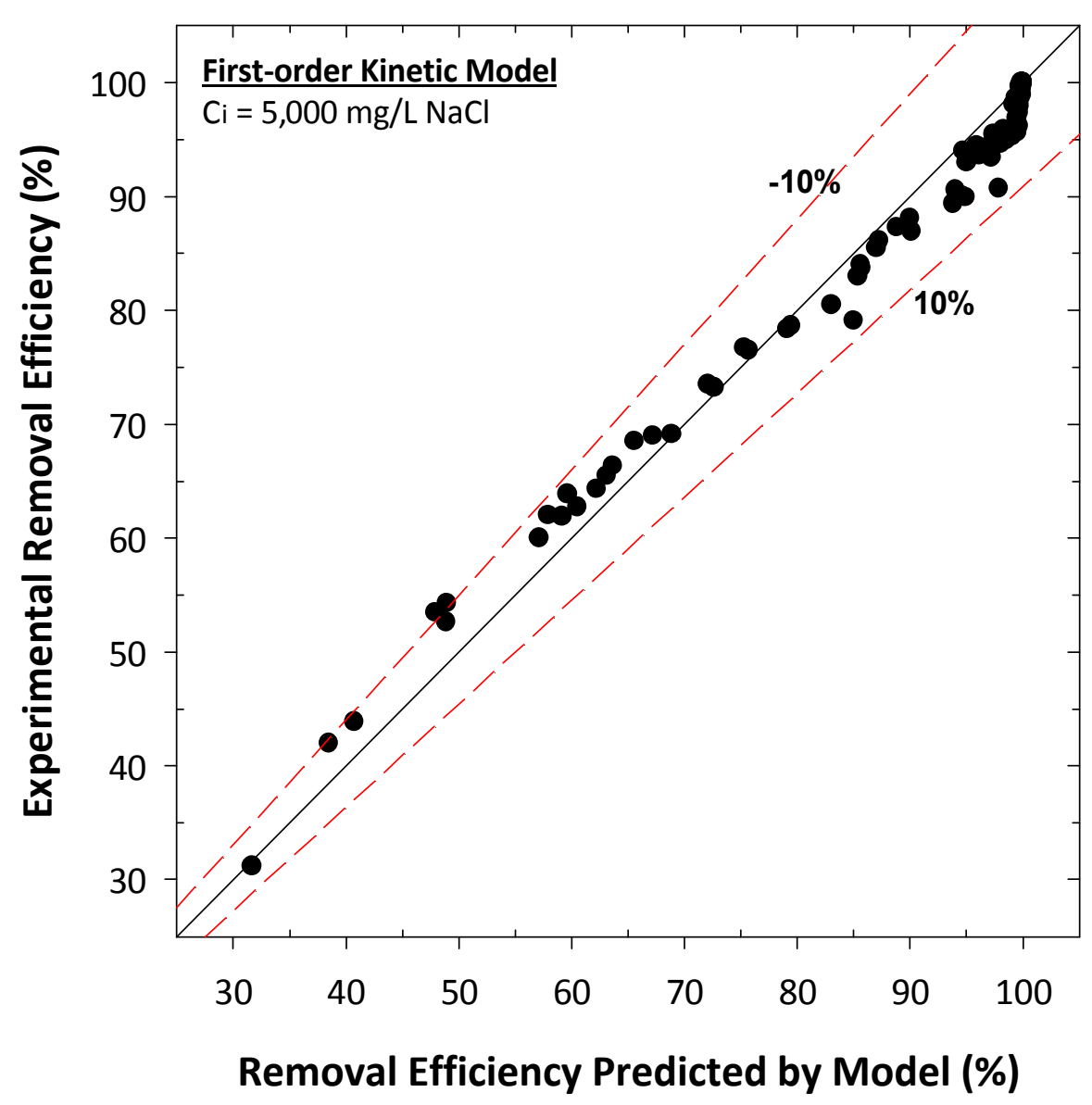


Fig. 5.

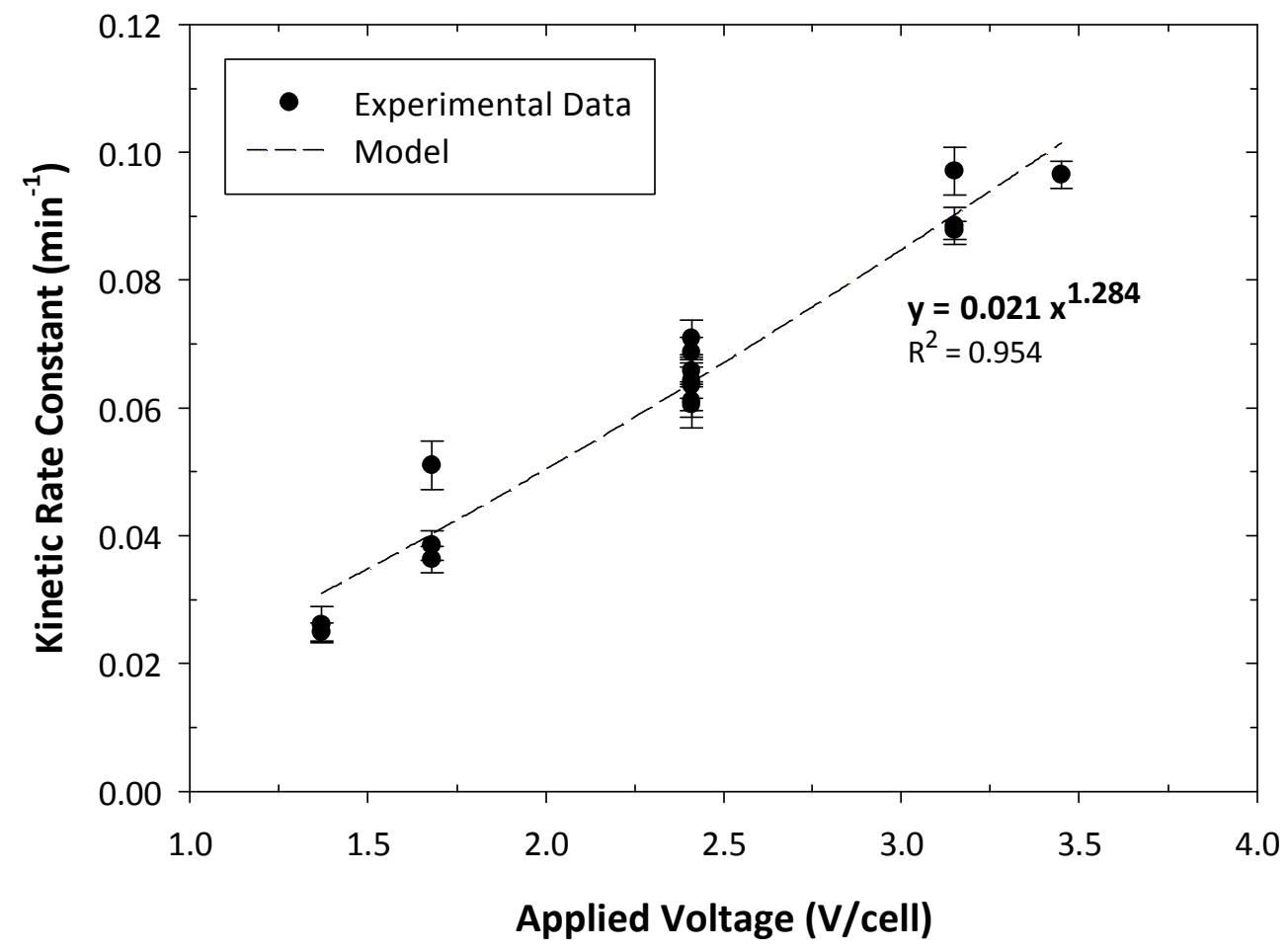


Fig. 6.

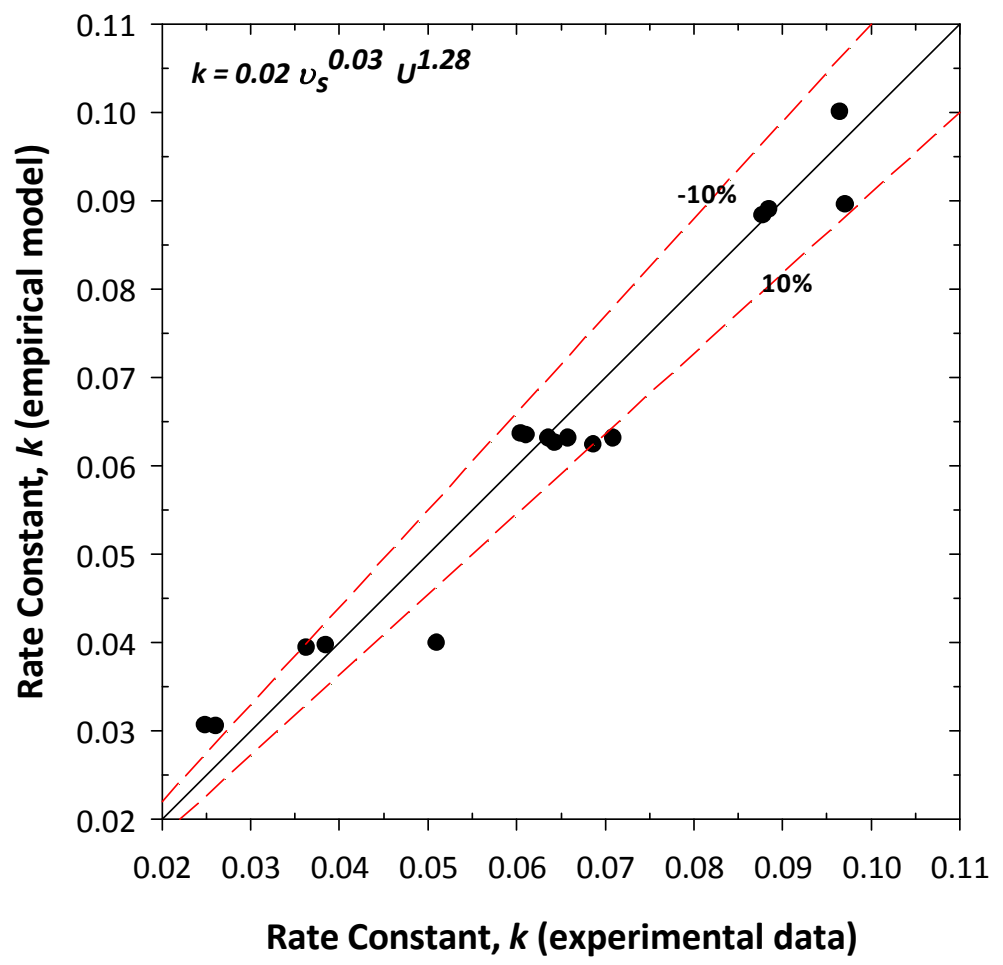


Fig. 7

(a)

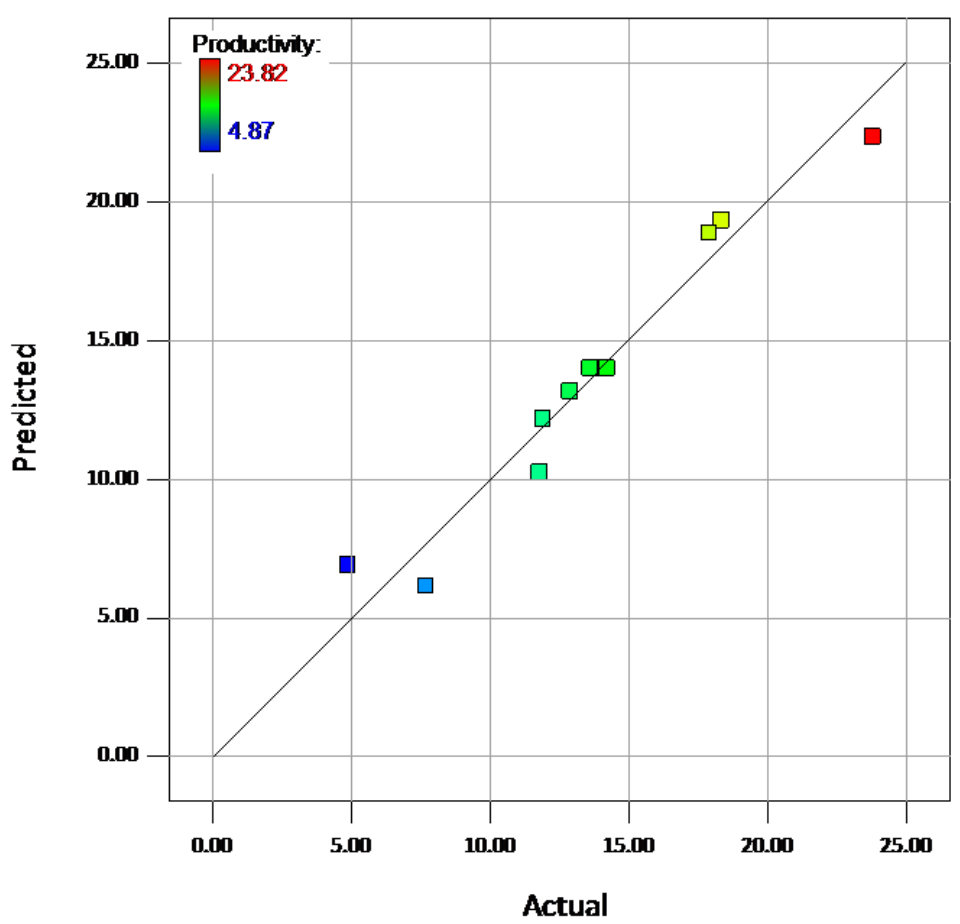

(b)

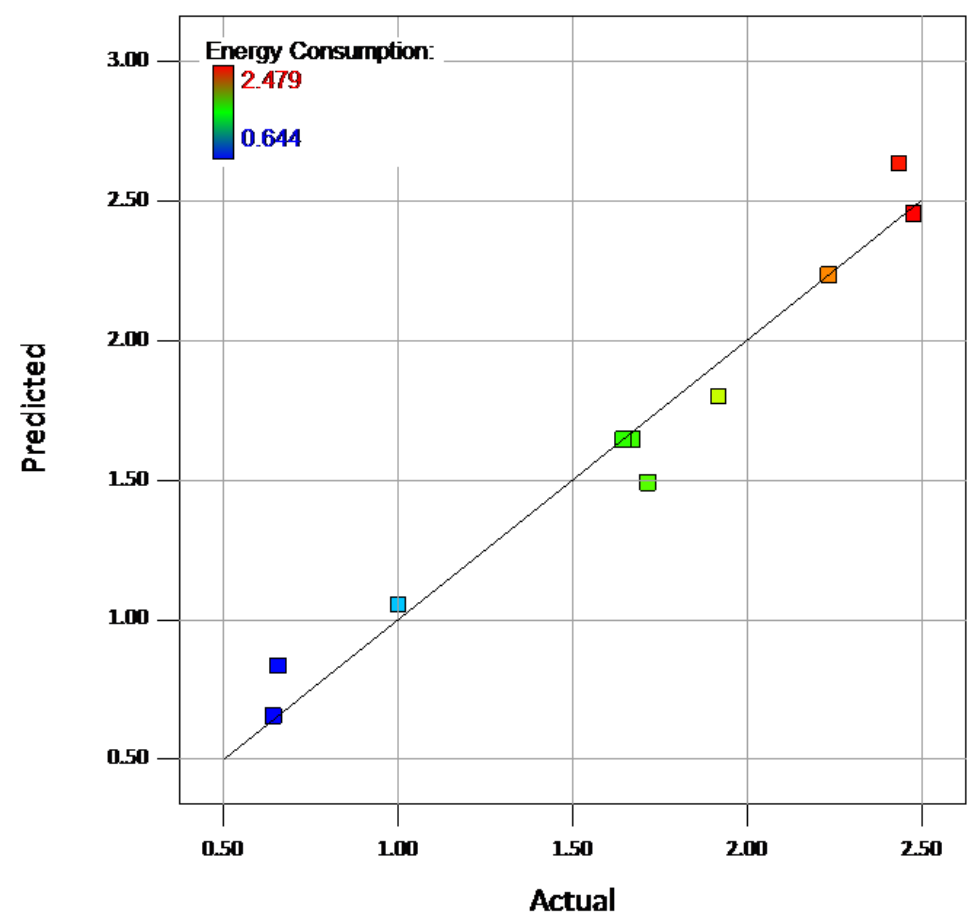


Fig. 8.

(a)

(b)
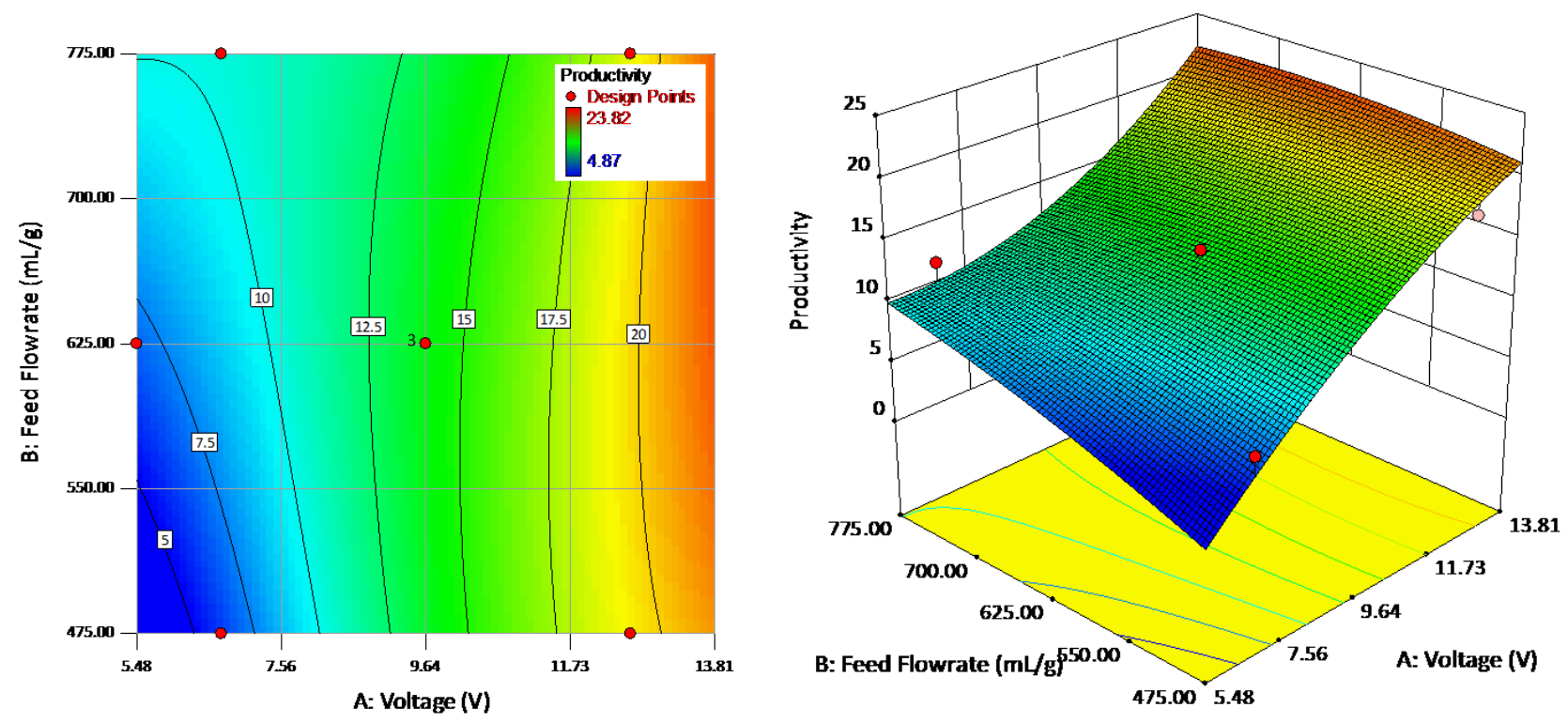

(c)

(d)
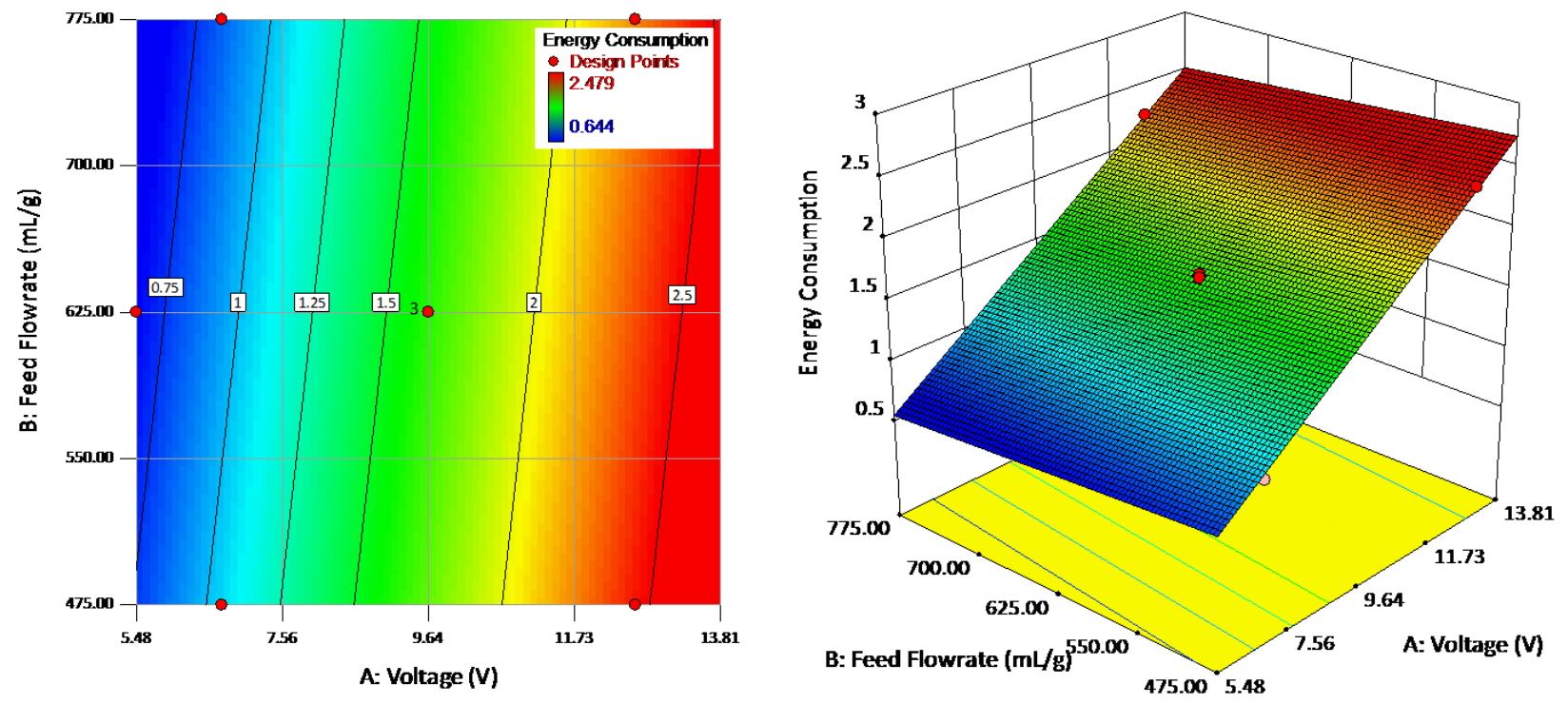
Fig. 9.

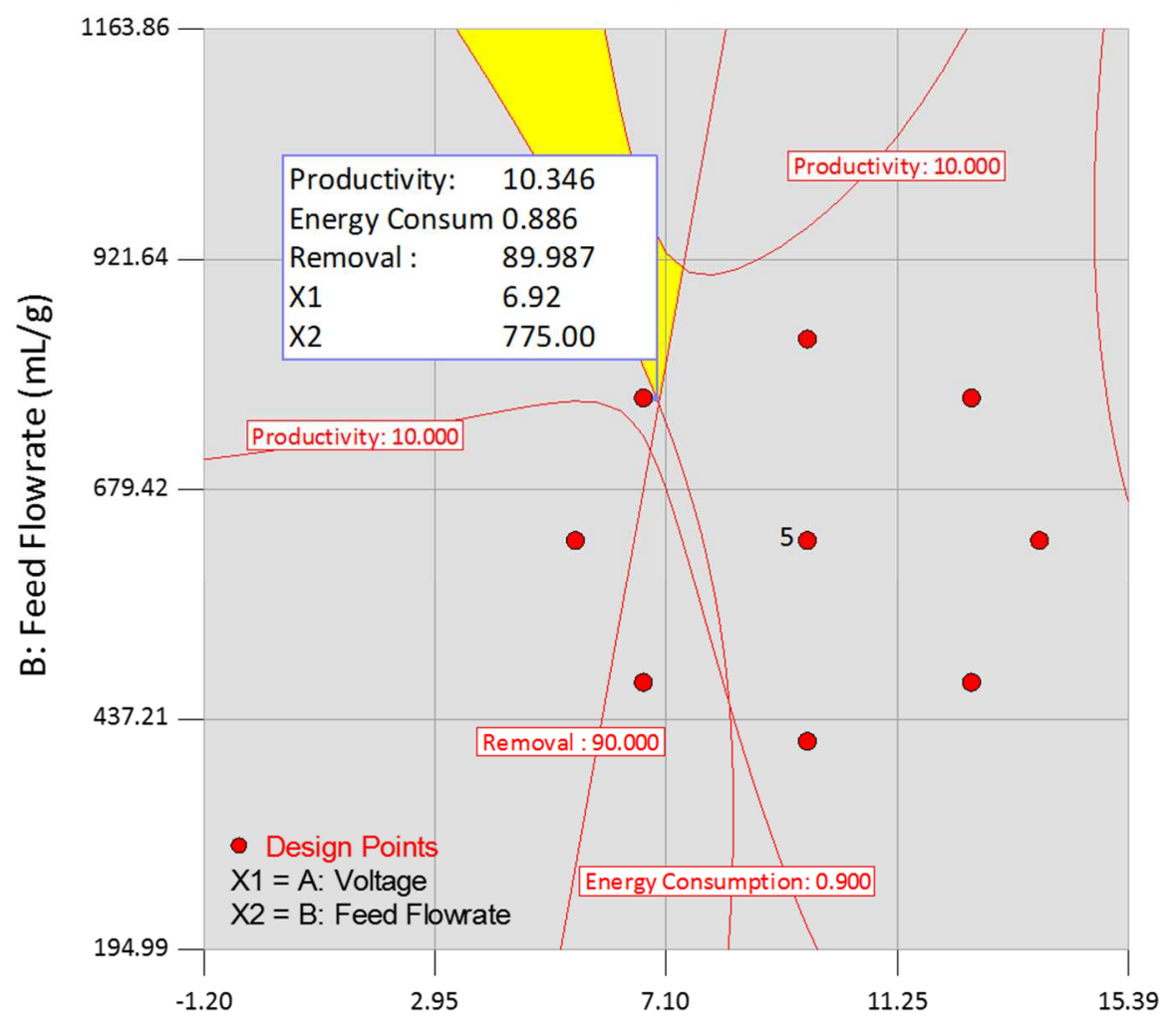

A: Total Voltage (V) for Four Cell-Pair Stack 